\section{An online supplemental issue for EJHP}

\author{
Phil Wiffen
}

I am very happy to present European Journal of Hospital Pharmacy's first online supplement focusing on clinical pharmacy activities. This issue is timed to coincide with the 2018 European Association of Hospital Pharmacists Congress and we are making all the articles free to access until the 2019 Congress. So why are we producing an online-only issue?

First let me say that there is no intention of moving away from a paper issue and we see many advantages in such a format-that will continue. Over the last 5 years or so we have actively promoted the concept of publishing research

Correspondence to Professor Phil Wiffen, Pain Research Unit, Churchill Hospital, Oxford OX3 7LE, UK; phil.wiffen@ndcn.ox.ac.uk to hospital pharmacists and seen the benefit of such an approach in terms of both the number of submissions and a real increase in quality. In addition we regularly support first-time authors to bring their papers to a level suitable for publication. The volume of submissions means that we can be more selective in terms of ensuring a range of topics, from authors across the globe and seeking to ensure that each issue has something of interest for each reader. The downside of such riches is that the delay of a paper reaching a print version is now a number of months and so this issue will increase the visibility of these key papers.

In this online issue we have chosen papers that cover clinical pharmacy topics across a wide range of healthcare needs from neonatal intensive care to elderly care and for a wide range of clinical specialties including the use of antibiotics. I hope that the issue will encourage hospital pharmacies with well-established clinical services to extend their range further and for those where clinical pharmacy is still in its infancy to see what opportunities exist and to start to make things happen.

Funding The authors have not declared a specific grant for this research from any funding agency in the public, commercial or not-for-profit sectors.

Competing interests None declared.

Provenance and peer review Commissioned; internally peer reviewed.

(C) European Association of Hospital Pharmacists (unless otherwise stated in the text of the article) 2018. All rights reserved. No commercial use is permitted unless otherwise expressly granted.

\section{Check for updates}

To cite Wiffen P. Eur J Hosp Pharm 2018;25:e1.

Eur J Hosp Pharm 2018;25:e1.

doi:10.1136/ejhpharm-2018-001556 